the NSW Vaccine Centre. To coincide with the program, a communication strategy is implemented. This includes media releases, advice to public health units and general practitioners and all other service providers, an information kit, information on the web, and a 'road show' to area health services and general practitioner divisions.

\section{FUTURE CONSIDERATIONS}

Issues that may need to be considered in future include the need for two doses and/or booster doses of the vaccine. A new combined vaccine for measles, mumps, rubella and varicella was licensed in the United States in 2005. Another issue will be surveillance for varicella zoster. Although many Australian states are planning to make this a notifiable disease in association with the new vaccination program, at this stage NSW is planning to use alternative forms of surveillance including varicella-related hospitalisations and deaths and periodic serosurveys. NSW will also investigate the feasibility of sentinel surveillance. As the incidence of varicella infections declines with time, the feasibility of statewide surveillance will be reviewed.

\section{REFERENCES}

1. Macartney KK, Beutels P, McIntyre P, et al. Varicella vaccination in Australia. J Paediatr Child Health 2005; 41(11): 541-619.

2. Brotherton J, McIntyre P, Peuch M, et al. Vaccine preventable diseases and vaccination coverage in Australia, 2001 to 2002. Comm Dis Intell 2004; 28 Suppl 2: viii-S116.

3. Nguygen HQ, Jumaan AO, Seward JF. Decline in mortality due to varicella after implementation of varicella vaccination in the United States. N Engl J Med 2005; 352(5): 450-8.

4. Davis MM, Patel MS, Gebremariam A. Decline in varicellarelated hospitalizations and expenditures for children and adults after introduction of varicella vaccine in the United States. Pediatrics 2004; 114(3): 786-92.

5. Oxman MN, Levin MJ, Johnson GR, et al. A vaccine to prevent herpes zoster and postherpetic neuralgia in older adults. N Engl J Med 2005; 352(22): 2271-84.

6. Gidding HF, Brisson M, Macintyre CR, Burgess MA. Modelling the impact of vaccination on the epidemiology of varicella zoster virus in Australia. Aust N Z J Public Health 2005 Dec; 29(6): 544-51. 圈

\title{
COMMUNICABLE DISEASES REPORT NSW FOR SEPTEMBER AND OCTOBER 2005
}

For updated information, including data and facts on specific diseases, visit www.health.nsw.gov.au and click on Infectious Diseases.

\section{TRENDS}

Tables 2 and 3 and Figure 1 show reports of communicable diseases received through to the end of September and October 2005 in NSW.

Data from the NSW Influenza Surveillance Program www. health.nsw.gov.au/infect/pdf/flureport.pdf show that the 2005 influenza season peaked in late August and had declined to baseline levels by mid October. Most cases were due to the influenza A virus. A small number were due to the influenza B virus, especially towards the end of the season.

Reports of pertussis cases appear to have peaked in NSW in August when 759 patients reported onset of symptoms. Nonetheless, pertussis remains common throughout the state (555 cases were reported in October), and clinicians should consider the diagnosis in people presenting with persistent bouts of coughing, especially when associated with an inspiratory whoop or vomiting. Treatment of the patient, if given within three weeks of onset, reduces infectiousness. It is important to identify other people who may be at risk of pertussis in whom infection could be severe, and who would benefit from receiving preventive antibiotics.

Prophylaxis is recommended for the following contacts of people infected with pertussis:

- all household members where the household includes an infant less than 12 months of age, a child aged between 12 and 24 months who has received fewer than three doses of pertussis vaccine, or a woman in the final month of pregnancy

- household members who have close dealings (within one metre) with children under five years old or with pregnant women

- where the person attended childcare for more than one hour while infectious, then other children and adults in the same classroom who are infants less than 12 months of age (regardless of vaccination status); other children aged 12 to 59 months who have received fewer than three doses of pertussis vaccine; or staff who have not received a pertussis vaccine in the previous 10 years

- infants less than 12 months of age, children aged between 12 and 24 months who have received fewer than three doses of pertussis vaccine, and women in the last month of pregnancy who were cared for (at a 
distance of within one metre) by the person for at least one hour while infectious

- unvaccinated health care workers who were exposed (came within one metre) to the infectious case for more than one hour, if the health care worker is to care for children under two years of age in the next two weeks.

Antibiotic prophylaxis is generally not considered valuable in other settings such as primary schools, high schools, tertiary institutions and work places, as prevention of transmission in these settings is unlikely. Call your public health unit for advice.

The mosquito-borne diseases Ross River virus infection and Barmah Forest virus infection tend to increase around Christmas and peak around Easter. The main risk of infection is in non-metropolitan areas, so residents and visitors to these areas should protect themselves by avoiding being bitten by mosquitoes. This involves staying inside when mosquitoes are most active (around dusk and dawn); wearing loose fitting, light coloured clothing that covers the arms and legs when outside; using an insect repellent; fitting fly screens to all windows, doors and chimneys and keeping them in good repair; using a knockdown insecticide in bedrooms (according to the manufacturer's instructions) half an hour before going to bed; and removing pools of water in which mosquitoes might breed from around the house.

\section{ENTERIC DISEASE}

Eleven outbreaks of gastroenteritis in institutions, involving at least 130 cases, were reported by public health units in September, including four in childcare settings, four in aged care facilities and three in hospitals. While the causative agent was not identified in most, rotavirus was confirmed in one childcare outbreak. From July to September 2005, at least 30 outbreaks of gastroenteritis in institutions (involving 382 cases) were investigated by public health units. This number is much lower than for the same period in 2004, when 161 outbreaks (involving 4896 cases) were reported. It is thought that the emergence of a new strain of norovirus in NSW in 2004 may have accounted for the large number of outbreaks that year.

On 26 September, Clark County Health District, located in Las Vegas in the United States, reported that a food handler at an international conference there had developed hepatitis A. On 13 and 14 September-while infectiousthe food handler had served approximately 1000 soft serve ice-cream cones with bare hands to attendees of the conference. Nonetheless, public health officials in Las Vegas deemed the risk of contamination of ice cream to be low. Of the 26,000 conference attendees, it was thought that 187 resided in NSW. NSW Health sent these people a letter advising them that they might have been exposed to the disease and should seek medical care if they developed symptoms.

\section{INVESTIGATION OF A CLUSTER OF SALMONELLOSIS}

In early September staff at the Randwick office of the South Eastern Sydney / Illawarra Public Health Unit reported two cases of Salmonella typhimurium phage type 9 (STM9) infection. Both individuals had South American names and had attended the same social club during their incubation periods. A review of statewide laboratory notifications identified another six people with STM9 infection who also had South American sounding names. On interview, five of the eight infected people reported that they had attended the same social club between 29 July and 8 August 2005.

A case series investigation was conducted in an attempt to identify and control the likely source of the apparent outbreak. A possible case of disease was defined as a laboratory-confirmed STM9 infection or untyped STM infection in a person with a South American sounding name who was a NSW resident with a specimen collection date since 15 July 2005. Possible cases were interviewed by public health unit staff using a questionnaire that included questions about whether they attended the club and what foods they ate at the club or from a bakery that supplied the club with specialty salad and pastries.

Seventeen possible cases were identified, or whom 12 were later found to have STM9. Apart from the five cases (all confirmed to have STM9) who were known to have eaten at the club, none of the other possible cases reported attending the club. One case with STM9 did report perhaps purchasing food items in the exposure period from the bakery.

Of the five cases linked to the club, food items reportedly consumed included barbeque steak $(n=1)$, grilled beef $(n=1)$, beef schnitzel $(n=2)$, speciality sausage $(n=1)$, pastries $(n=3)$, chips $(n=1)$, specialty salad $(n=2)$ and unspecified salad $(\mathrm{n}=1)$.

The NSW Food Authority undertook an environmental investigation of the club and the bakery, and collected food samples for testing. No likely source of infection was identified at either the club or the bakery. None of the food samples, including the specialty salad and pastries, showed the presence of any organisms. (However, the samples were collected approximately one month after the people who became infected had attended the club.) The specialty salad was prepared with a homemade mayonnaise that used raw egg and was supplied by the bakery.

The source of the outbreak remains undetermined. As a precaution, the bakery was advised by the NSW Food Authority to use pasteurised egg in the mayonnaise, rather than raw egg. No further cases linked to the club have been identified and there is no evidence of ongoing risk of transmission related to this cluster.

In October 2005 notifications of salmonellosis (including paratyphoid infections) increased to 167 , compared with 
92 cases in September. There were 119 notifications in October 2004. Several salmonellosis outbreaks were under investigation by public health units in collaboration with the NSW Food Authority in October 2005, relating to:

- five cases of Salmonella Anatum across NSW

- eight confirmed and 22 probable cases of Salmonella Typhimurium (STM) phage type 197 infection among attendees of a childcare centre located in South Eastern Sydney / Illawarra Area Health Service

- three cases of Salmonella Birkenhead infection in residents of a facility located in North Sydney / Central Coast Area Health Service

- four cases of STM135a infection in Sydney South West Area residents

- four cases of STM170/108 infection linked to two large functions at a café located in Sydney South West Area.

Cryptosporidiosis infections increased in October with 37 notifications, compared with 12 in September. This was a more than three-fold increase compared to October in previous years and may be related to changes in testing procedures by laboratories. No common exposures have been identified among cases.

\section{AVIAN INFLUENZA AND PANDEMIC PLANNING}

In his report of 27 April 1920, Robert T Paton, the DirectorGeneral of Public Health in NSW, noted that the 1919 influenza epidemic occurred in two waves, each of about 10 weeks duration. While the first wave (from 19 March to 27 May) was bad enough, with 1892 deaths recorded, the second wave (from 28 May to 25 August) was terrible, causing 3989 deaths. The investigation by the Department of Public Health found that the highest death rates were in the most densely populated areas, and among workingaged males. For all of 1919 (when about 2 million people lived in NSW), 6387 deaths from influenza were reported, representing 24 per cent of all deaths for that year.

Mr Paton's report is a salient reminder of the havoc that a new strain of influenza can cause to humans. Since late 2003, an epidemic of avian influenza affecting both bird flocks and humans has been occurring in Asia. This epidemic in birds is caused by the H5N1 strain of influenza virus and is unprecedented in its geographical spread. It is highly unlikely that it will be eradicated in these countries in the short term. The World Health Organization (WHO) has reported that as of 24 October 2005, in Thailand, Vietnam, Cambodia and Indonesia there have been 121 human cases of avian influenza and 62 deaths. Although clusters of human cases have been reported, none of these reports have definitively demonstrated human-to-human transmission. So the current outbreak of H5N1 avian influenza in Asia and parts of eastern Europe is a disease primarily of birds, not humans.
However, in recent weeks, analyses of reconstructed virus from the 1918-1919 influenza pandemic have suggested that that virus adapted to humans directly from an avian-like virus, rather than from re-assortment with co-exiting human viruses. ${ }^{1}$ These data support the fears of many scientists that the current H5N1 virus could also adapt to infect humans, as the 1918 strain seems to have done.

Influenza pandemics occur every 10 to 50 years when an influenza virus strain develops to which humans have little or no immunity. The Spanish flu of 1918-1919 was the most severe pandemic of the last century, killing between 20 and 40 million people worldwide. The most recent pandemic, the Hong Kong flu, occurred in 1968 and was far milder, causing one million deaths. This virus was thought to have arisen from re-assortment of influenza viruses rather than adaptation of an avian strain. WHO is closely monitoring changes to the makeup and behaviour of the H5N1 virus in order to assess any change in pandemic risk. Using the WHO seven-point pandemic phase scale, the world at present is at 'Pandemic alert period-Global phase 3' (human infections with a new subtype overseas, with rare instances of spread to a close contact of a case). Despite recent reports suggesting that the H5N1 strain may be transforming into a more dangerous form, an expert committee of the WHO recommended in June 2005 that the world pandemic alert level not be raised from the current level, which has been in effect since January 2004.

Pandemic preparedness is now a major concern of governments. Internationally, the WHO has taken the lead role and in April 2005 released the WHO global influenza preparedness plan. At the national level, in June 2005 the Australian Government released the Australian Management Plan for Pandemic Influenza; see www. health.gov.au/internet/wcms/Publishing.nsf/Content/phdpandemic-plan.htm.

NSW Health has carried out a number of preparedness activities. These included Exercise Warning Shot in 2003, which exercised the public health network's preparedness for an influenza pandemic, and in late 2004 the Infectious Diseases Emergencies Workshop-Planning a Way Forward, involving over a hundred clinicians, public health and other health professionals. Ongoing preparedness activities include:

- participation in the National Influenza Pandemic Action Committee

- revision of the NSW Health Influenza Pandemic Plan, which will include protocols for the management of cases

- expert consultation through the NSW Infectious Disease Emergency Advisory Group

- development of planning frameworks for area health services 
- improving the emergency supply of personal protective equipment and antiviral medicines

- improving communications systems for health care workers

- developing and conducting preparedness exercises

- participating in Exercise Eleusis, a national exercise designed to test Australia's response to an incursion of avian influenza, planned for late 2005.

Preparing for a pandemic of influenza is a continuous process, and plans will need to be updated as new information about the threat, and new response technologies, emerge. For more information about avian influenza and pandemic preparedness, see www.health.nsw.gov.au and click on Infectious Diseases.

\section{Reference}

1. Taubenberger JK, Reid AH, Lourens RM, Wang R, Jin G, Fanning TG. Characterization of the 1918 influenza virus polymerase genes. Nature 2005; 437: 889-93.

\section{QUARTERLY REPORT: AUSTRALIAN CHILDHOOD IMMUNISATION REGISTER}

Table 1 compares the percentages of fully immunised Indigenous and non-Indigenous children in NSW aged 12 months to less than 15 months in each area health service, reported by all service providers.

These data refer to children whose age has been calculated 90 days before data extraction. The information contained in the report has been extracted from the Australian Childhood Immunisation Register and may be underestimated by approximately three per cent due to children being vaccinated late or to service providers failing to forward information to the register. 중

\section{TABLE 1}

PERCENTAGE OF FULLY IMMUNISED CHILDREN AGED 12 MONTHS TO LESS THAN 15 MONTHS BY AREA HEALTH SERVICES AND BY INDIGENOUS AND NON-INDIGENOUS STATUS

\begin{tabular}{|c|c|c|c|c|c|c|}
\hline \multirow[b]{2}{*}{ Area Health Service } & \multicolumn{2}{|c|}{$30 / 06 / 2005$} & \multicolumn{2}{|c|}{$30 / 09 / 2005$} & \multicolumn{2}{|c|}{$31 / 12 / 2005$} \\
\hline & $\begin{array}{c}\text { Non-Indigenous } \\
\%\end{array}$ & $\begin{array}{c}\text { Indigenous } \\
\% \\
\end{array}$ & $\begin{array}{c}\text { Non-Indigenous } \\
\%\end{array}$ & $\begin{array}{c}\text { Indigenous } \\
\% \\
\end{array}$ & $\begin{array}{c}\text { Non-Indigenous } \\
\%\end{array}$ & $\begin{array}{c}\text { Indigenous } \\
\%\end{array}$ \\
\hline Greater Southern & 93 & 91 & 93 & 88 & 94 & 91 \\
\hline Greater Western & 92 & 81 & 92 & 84 & 90 & 85 \\
\hline Hunter / New England & 94 & 87 & 93 & 82 & 93 & 86 \\
\hline North Coast & 83 & 83 & 85 & 78 & 86 & 83 \\
\hline Northern Sydney / Central Coast & 91 & 92 & 91 & 96 & 91 & 97 \\
\hline South Eastern Sydney / Illawarra & 90 & 91 & 90 & 83 & 91 & 90 \\
\hline Sydney South West & 90 & 83 & 90 & 83 & 89 & 89 \\
\hline Sydney West & 90 & 93 & 90 & 90 & 90 & 84 \\
\hline NSW & 91 & 87 & 91 & 85 & 91 & 88 \\
\hline
\end{tabular}


FIGURE 1

REPORTS OF SELECTED COMMUNICABLE DISEASES, NSW, JAN 2000 TO OCT 2005, BY MONTH OF ONSET

Preliminary data: case counts in recent months may increase because of reporting delays.

Laboratory-confirmed cases only, except for measles, meningococcal disease and pertussis $\mathrm{BFV}=$ Barmah Forest virus infections,

$\mathrm{RRV}=$ Ross River virus infections

Lab conf $=$ laboratory confirmed
Men Gp C and Gp B = meningococcal disease due to serogroup $C$ and serogroup $B$ infection, other/unk = other or unknown serogroups.

NB: multiple series in graphs are stacked, except gastroenteritis outbreaks.

NB: Outbreaks are more likely to be reported by nursing homes and hospitals than by other institutions

\begin{tabular}{lr}
\hline \multicolumn{2}{|l|}{ NSW population } \\
Male & $50 \%$ \\
$<5$ yrs & $7 \%$ \\
$5-24$ yrs & $27 \%$ \\
$25-64$ yrs & $53 \%$ \\
$65+$ yrs & $13 \%$ \\
Rural & $46 \%$
\end{tabular}

\begin{tabular}{|rc|}
\hline \multicolumn{2}{|c|}{ Aug 05-Oct 05 } \\
Male & $51 \%$ \\
$<5$ & $0 \%$ \\
$5-24$ & $12 \%$ \\
$25-64$ & $73 \%$ \\
$65+$ & $15 \%$ \\
Rural & $95 \%$ \\
\hline
\end{tabular}

Rural $95 \%$

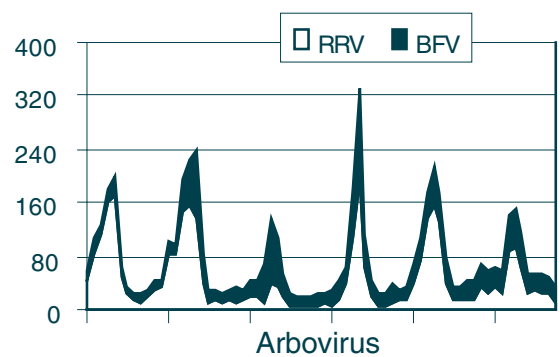

\begin{tabular}{|rc|}
\hline \multicolumn{2}{|c|}{ Aug 05-Oct 05 } \\
Male & $61 \%$ \\
$<5$ & $28 \%$ \\
$5-24$ & $39 \%$ \\
$25-64$ & $32 \%$ \\
$65+$ & $1 \%$ \\
Rural & $44 \%$ \\
\hline
\end{tabular}
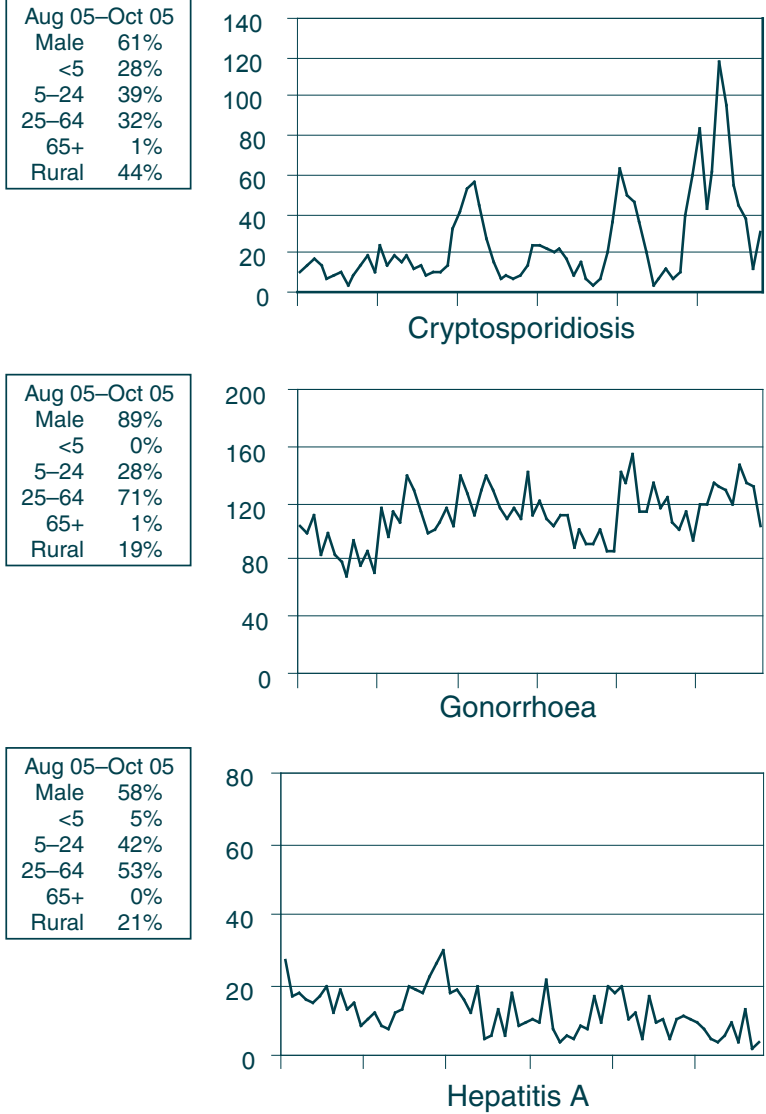

\begin{tabular}{|lr|}
\hline \multicolumn{2}{|c|}{ Aug 05-Oct 05 } \\
All outbreaks & 32 \\
Nursing homes & 16 \\
Hospitals & 3 \\
Child care & 13 \\
Schools & 0 \\
Other & 0 \\
\hline
\end{tabular}

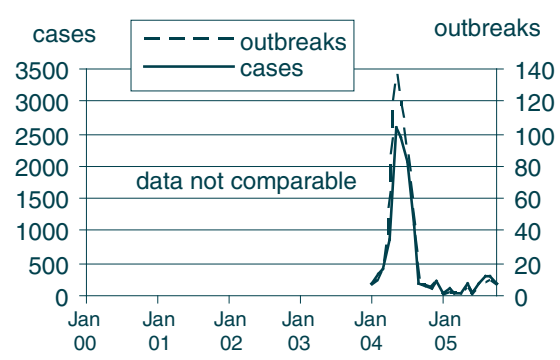

Gastroenteritis outbreaks in institutions

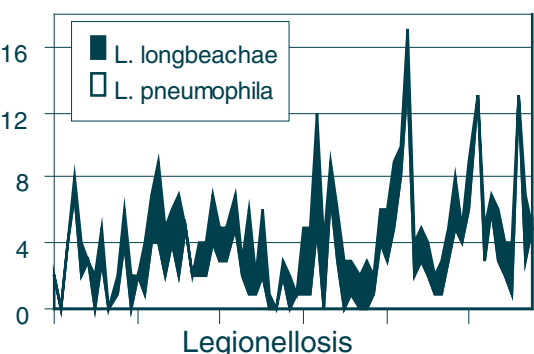

Aug 05-Oct 05 Male $56 \%$ $<5$ $5-24 \quad 4 \%$ 25-64 $72 \%$ $65+\quad 24 \%$ Rural $\quad 40 \%$

Legionellosis

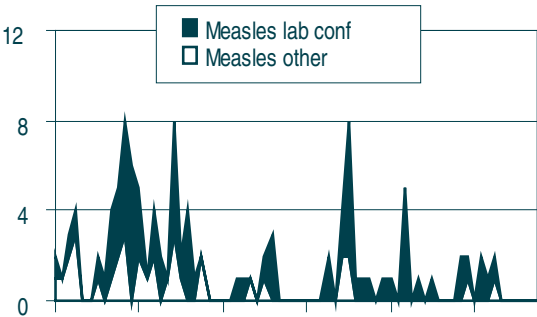

Measles

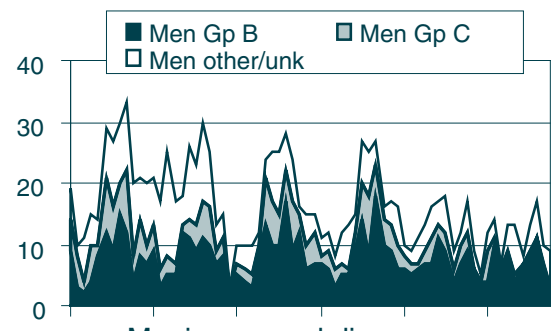

Aug 05-Oct 05 Male $56 \%$ $<5$
$-50 \%$ 5-24 25\%

$65+17 \%$

Rural $64 \%$

\begin{tabular}{cc}
\multicolumn{2}{|c}{ Aug 05-Oct 05 } \\
Male & $0 \%$ \\
$<5$ & $0 \%$ \\
$5-24$ & $0 \%$ \\
$25-64$ & $0 \%$ \\
$65+$ & $0 \%$ \\
Rural & $0 \%$
\end{tabular}

Meningococcal disease

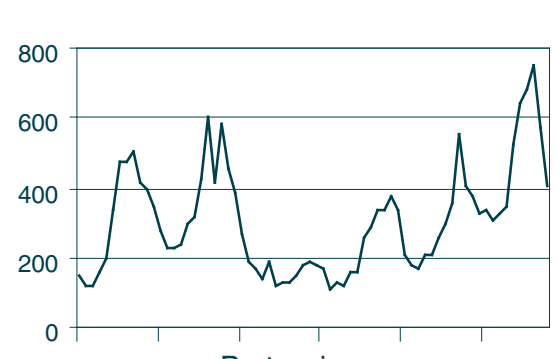

Pertussis

Salmonella infections

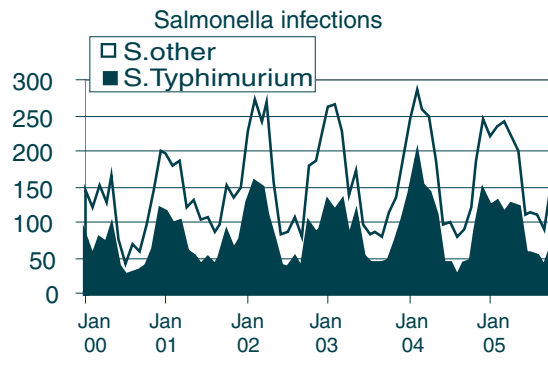

Salmonella infections 


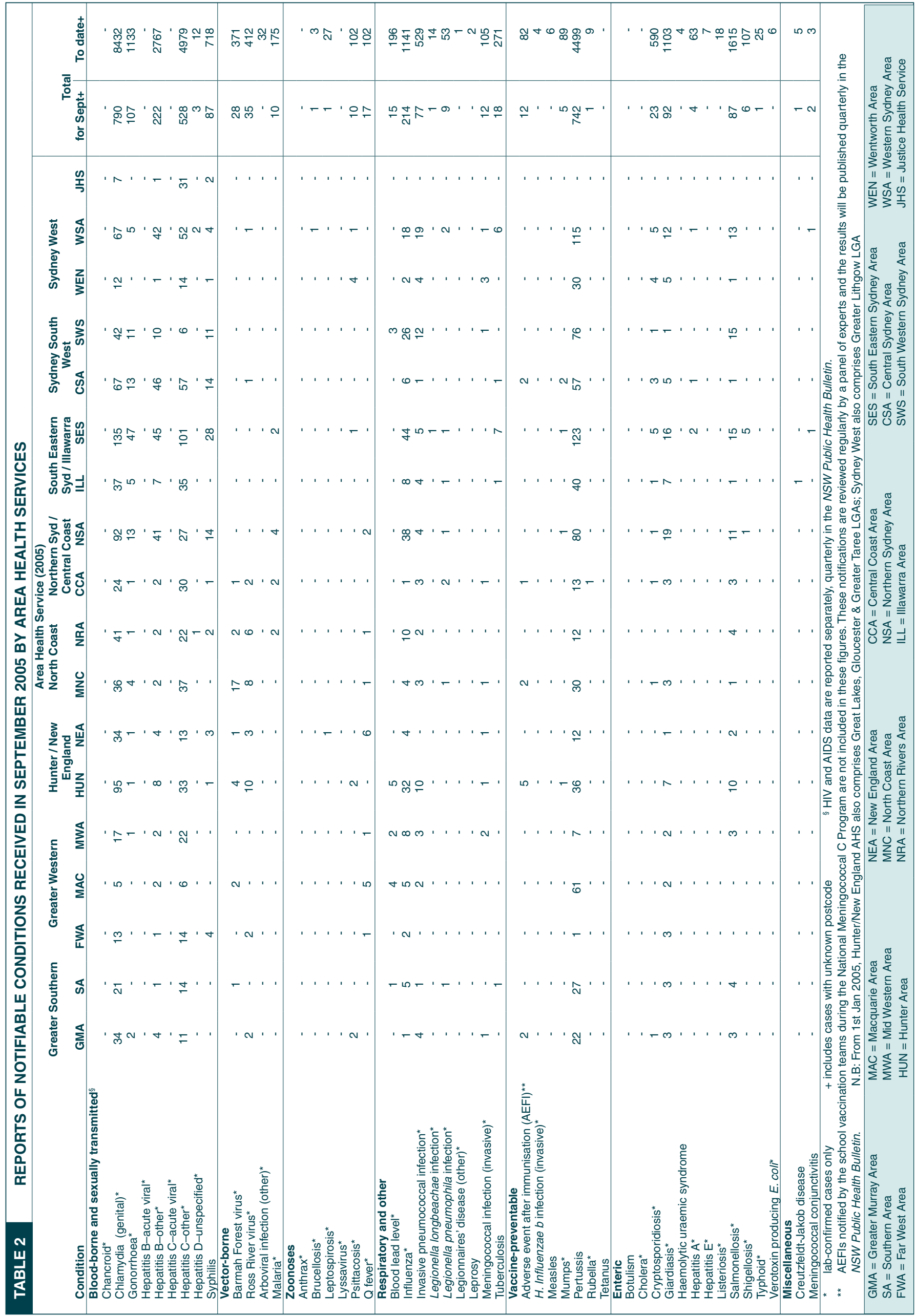




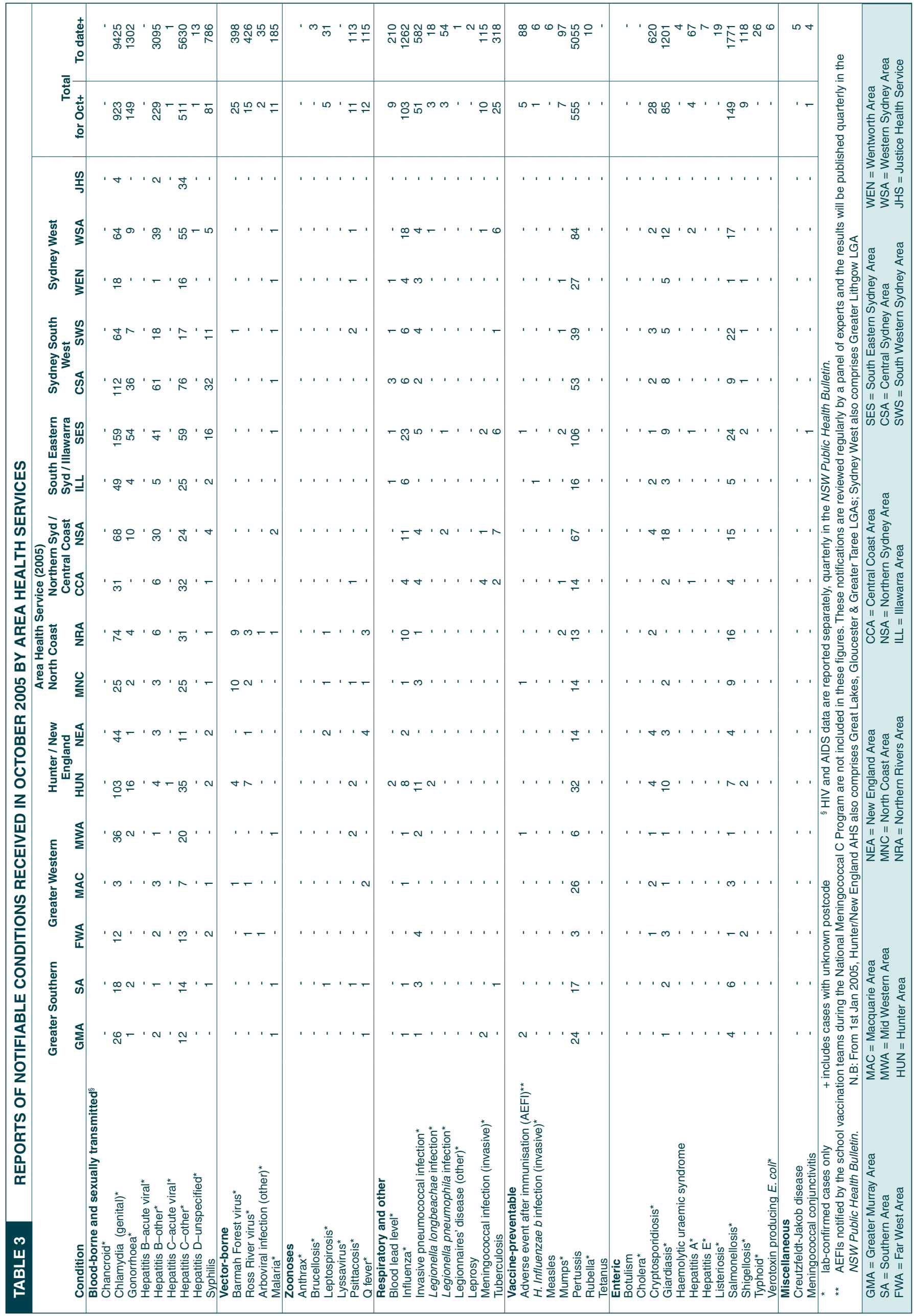

